\title{
Pendekatan Antropometri Kaki Orang Indonesia Pada Desain Master Shoe Last Bagi Industri Kecil Dan Menengah
}

\author{
Mohamad Arif Waskito ${ }^{1}$, Caecilia Sri Wahyuning ${ }^{2}$ \\ ${ }^{1}$ Jurusan Desain Produk - Fakultas Seni Rupa dan Desain \\ ${ }^{2}$ Jurusan Teknik Industri - Fakultas Teknologi Industri \\ Institut Teknologi Nasional \\ Jl. PKH Mustopha 23 Bandung \\ Imawaskito@itenas.ac.id
}

Penelitian ini bertujuan untuk mengevaluasi faktor yang memengaruhi kualitas shoe last (cetakan sepatu) di Industri Kecil dan Menengah (IKM) persepatuan dilihat dari ukuran (penomoran) dan bentuk shoe last tersebut. Produk sepatu dituntut memiliki kenyamanan sebagai salah satu aspek penting dalam perancangannya. Aspek kenyaman ditentukan oleh ukuran dan bentuk shoe last yang dipengaruhi oleh kualitas ketepatan ukuran dan bentuk master shoe last-nya. Kualitas ukuran dan bentuk shoe last belum dilihat sebagai salah satu aspek penting oleh pengrajin di IKM persepatuan. Umumnya mereka lebih mengutamakan aspek modelnya saja yang lebih diprioritaskan. Oleh karena itu, terdapat ketidakseragaman ukuran dalam penomoran sepatu dan ketidaksesuaian ukuran sepatu dengan standar ukuran pada sistem mondopoint maupun Eropa yang dibuat oleh para produsen. Selain itu, terjadi juga kesalahan proses pembentukan pada tahapan perancangan master shoe last. Perubahan bentuk kaki (punggung kaki/ lengkung kaki/ dan tumit) pada saat menggunakan sepatu/ sandal dan high heel, kurang diperhatikan oleh para pembuat master shoe last sehingga bentuk yang dihasilkan tidak sesuai dengan karakter kaki pengguna, khususnya orang Indonesia. Hal penting lainnya yang harus diperhatikan dalam pembuatan master shoe last, terdapat pada bentuk bagian toe-box dan back counter. Hasil penelitian ini adalah dihasilkannya sebuah prototype master shoe last untuk jenis sepatu high heel, yang telah disesuaikan dengan antropometri kaki dan karakteristik kaki orang Indonesia.

Kata kunci: antropometri kaki, desain master shoe last dan IKM.

\section{Indonesian Anthropometry Approach to the Master Shoe Last Design for Small and Medium Industries}

This study aims to evaluate factors that affect the quality of shoe last $\mathrm{n}$ small and medium scale industries, seen from the size (numbering) and the form of the shoe last. Shoe products are required to have comfort as one of the important aspects in its design. Comfort aspect is determined by the size, and shape of shoe last is influenced by the quality of the accuracy of the size and shape of the master shoe last. The quality of the size and shape of shoe last has not been seen as one of the important aspects by craftsmen in the small and medium scale industries of the footwear. Generally, they prioritize more on the modeling aspects. Therefore, there is no uniformity in shoe size numbering, and there is size mismatch with the standard size, namely, the mondopoint system as well as the European standard; and these are the results of errors made by the manufacturers. In addition, there is also an error in the formation process in the design stage of the master shoe last. Changes in the shape of the foot (foot / arch / heel) when using shoes / sandals and high heel, are less noticed by the makers of the master shoe last so that the resulting shape is not in accordance with the character of the user's feet, especially Indonesian people. Another important thing that must be considered in making master shoe last is the shape of the toe-box and back counter. The results of this study are the production of a master shoe last prototype for high heel, which has been designed to fit the anthropometry and the characteristics of Indonesian feet.

Keywords: foot anthropometry, shoe last masters design and small-scale industries.

Proses Review : 1 - 20 Agustus 2019, Dinyatakan Lolos: 22 Agustus 2019 


\section{PENDAHULUAN}

Kota Bandung merupakan pusat industri kreatif di Indonesia yang salah satunya adalah industri fesyen, khususnya industri sepatu. Namun demikian, masuknya produk sepatu dari luar negeri menyebabkan persaingan dalam industri persepatuan menjadi sangat ketat dan produk lokal tidak mampu bersaing dengan produk dari luar. Perancangan alas kaki telah dikembangkan sejak lama dan dalam beberapa penelitian tentang alas kaki selalu fokusnya pada ergonomi dan fisiologi (Lin \& Chen, 2015). Contohnya, perancangan alas kaki yang terutama berhak tinggi (high heel) secara umum masih mempertimbangkan aspek fashion/tampilan tanpa pertimbangan ergonomi dan menjadi penyebab permasalahan kaki (Lin \& Chen, 2015). Potensi high heels yang dapat menimbulkan cidera pada pemakai, seharusnya dipertimbangkan (Barnish \& Barnish, 2016). Beberapa hasil survey menunjukkan, bahwa pada umumnya konsumen memiliki ketidakpuasan terhadap beberapa aspek dari sepatu. Survey tehadap pengguna sepatu olah raga diketahui ada aspek kenyamanan, kesesuaian bentuk sepatu dengan kaki dan desain sepatu yang menjadi aspek ketidakpuasan yang tinggi (Azhari dkk, 2015). Pada survey terhadap penggunan high heel, sebagian besar ketidakpuasan terdapat pada aspek estetika dan kenyamanan sepatu (Waskito \& Wahyuning, 2013). Spesifikasi teknis yang berkontribusi terhadap estetika dan keamanan atau kenyamanan sepatu adalah model sepatu, dimensi dan bentuk kaki, bentuk pola, bahan dan proses perakitan sepatu (Waskito \& Wahyuning, 2013; Azhari dkk, 2015).

Permasalahan yang muncul pada konsumen akibat dimensi dan bentuk kaki, seringkali konsumen tidak memiliki kepastian terhadap nomor kaki. Kondisi ini, menyebabkan konsumen harus mencoba beberapa sepatu dengan nomor berbeda untuk model yang sama. Pegangan nomor kaki seorang konsumen tidak dapat dijadikan acuan seorang konsumen. Hal ini mengindikasikan, bahwa terdapat ketidakseragaman ukuran sepatu pada nomor dan model sepatu yang sama.

Salah satu spesifikasi teknis yang memengaruhi kenyamanan sepatu adalah dimensi dan bentuk kaki, yang ditentukan oleh bentuk shoe last (Waskito \& Wahyuning, 2013). Shoe last merupakan alat cetak sepatu yang dapat memberikan rupa, bentuk dan dimensi tertentu sebagai representasi kaki manusia (Gerdes, 2013). Proses pembuatan shoe last dalam pembuatan sepatu merupakan tahap penting, agar diperoleh sepatu yang nyaman dan sesuai dengan ukuran serta karakteristik/anatomi kaki pengguna. Para pengrajin sepatu memeroleh shoe last dari pembuat shoe last, yang merupakan proses duplikasi/replikasi dari master shoe last. Pada sistem produksi masal, master shoe last digunakan sebagai acuan utama untuk membuat shoelast-shoelast lainnya sesuai dengan penomoran yang berjenjang.
Penomoran sepatu mengacu pada ukuran panjang kaki, tetapi penentuan ukuran sepatu sangat dipengaruhi oleh kondisi kaki dengan berbagai proporsi ukuran dan bentuk. Bentuk dan ukuran tersebut berbeda pada setiap ras, jenis kelamin dan perilaku konsumen. Para pengrajin sepatu di Bandung menggunakan ukuran standar panjang alas kaki sistem Paris stitch (Perancis) dan Imperial (Inggris). Produksi sepatu dengan target pasar lokal dilandasi sistem pengukuran menggunakan sistem metrik/mondopoint, yang terlepas dari standar internasional (Waskito \& Wahyuning, 2013). Pada penelitian sebelumnya telah dilakukan pengukuran antropometri 201 orang dewasa untuk mengetahui kesesuaian antropometri kaki orang Indonesia dengan ukuran British, Amerika dan Eropa. Pada penelitian tersebut, ditemukan tidak terdapat perbedaan yang signifikan antara sistem ukuran baru dengan sistem ukuran sepatu British dan Amerika serta Eropa (Mardani, 2014). Industri kecil di Indonesia, pada umumnya menggunakan sistem penomoran French/Europe Sizes. Oleh karena itu, pada penelitian ini dikaji tentang kesesuaian antara ukuran panjang kaki responden dengan nomor sepatu yang digunakan. Penelitian ini juga untuk mengidentifikasi profil antropometri kaki, yang digunakan sebagai acuan dalam merancang dan membuat master shoe last. Hasil kajian ini, selanjutnya dapat digunakan oleh para pelaku IKM alas kaki dalam menentukan ukuran dan standarisasi shoe last mereka.

\section{METODE}

Penelitian ini dilakukan dengan pendekatan antropometri, yang tahapannya sebagai berikut.

\section{Objek Kajian}

Pada penelitian ini, objek kajiannya adalah wanita yang dalam kesehariannya menggunakan sepatu jenis high heel untuk bekerja. Survey dilakukan pada wanita pekerja dewasa, yang umumnya memiliki frekuensi lebih tinggi dalam pembelian sepatu.

\section{Pengukuran Antropometri}

Antropometri kaki partisipan, diukur pada siang hari memakai pita ukuran dan penggambaran bentuk telapak kaki pada selembar kertas (Gambar 1). Dimensi kaki yang diperlukan untuk membuat master shoe last (Gambar 2) adalah: keliling kaki/ball girth (a); keliling kaki/waist (b); keliling kaki/instep (c); panjang keliling tumit kaki/ length to heel (d); keliling angkle (e); dan panjang kaki/ foot length (f). Dimensi yang digunakan untuk penomoran sepatu adalah foot length.

\section{Metode Penomoran Kaki}

Ukuran sepatu yang digunakan partisipan, mengacu pada sistem ukuran dan penomoran yang universal. Pada umumnya, panjang dan desain sepatu mengacu pada beberapa sistem ukuran yang popular misalnya pada ukuran Peran- 


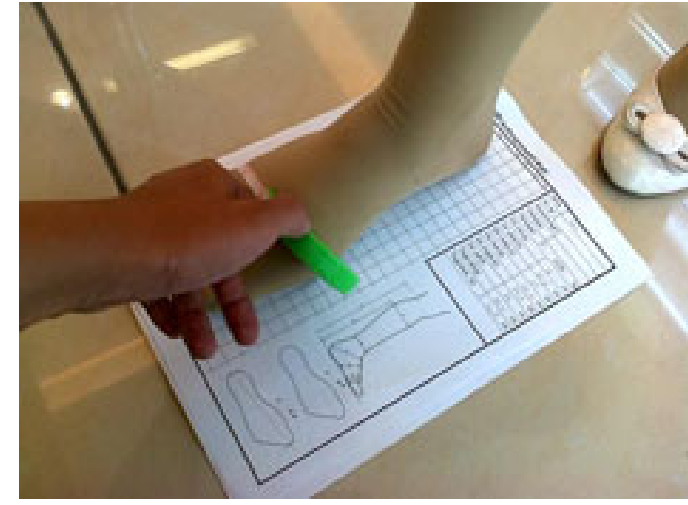

Gambar 1. Proses pengukuran antropometri kaki (Sumber: Dok. Pribadi, 2018)

cis, Inggris dan beberapa negara Eropa barat yang telah memperkenalkan sistem berbasis matrik (mondopoint). Matrik ini, adalah sistem yang dipakai menentukan penomoran sepatu yang digunakan di pasar lokal (Pivecka, 1994).
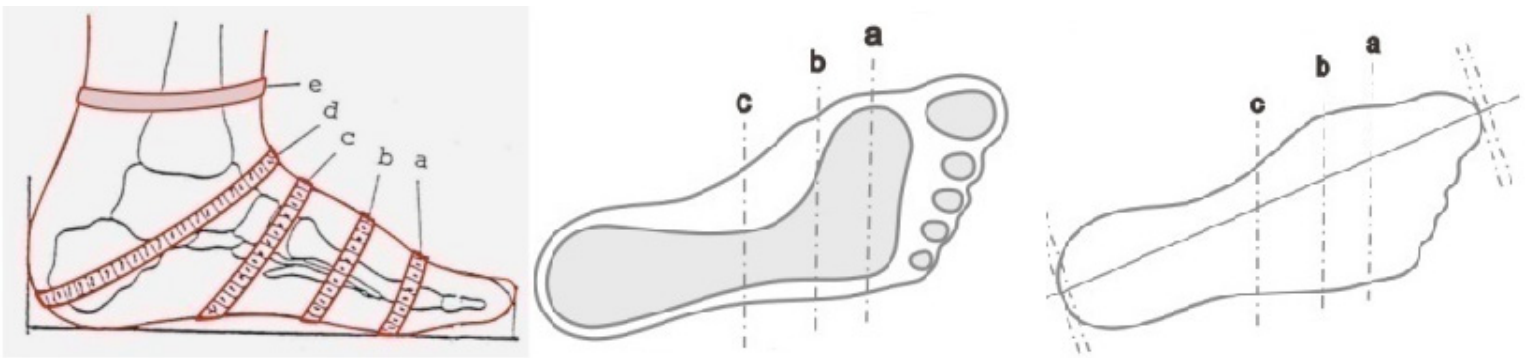

Gambar 2. Pengukuran antropometri kaki untuk shoe last

(Sumber: Practical Handbook on Shoe Production, 1994)
Dasar penomoran pada setiap sistem pengukuran yang berlaku umumnya adalah panjang kaki. Teknik pengukuran memakai sistem mondopoint, diajukan oleh Standar Internasional Organization (ISO 9407: 1991) tentang ukuran sepatu sebagai sistem penentuan ukuran dan penandaan. Sistem pengukuran ini berdasarkan pada panjang dan rerata lebar kaki untuk sepatu yang cocok, dalam satuan milimeter (Goonetilleke, 2012; shoesizes. co, 2018). Ukuran sepatu 24/95, menandakan panjang kaki $24 \mathrm{~cm}$ dan lebarnya ekivalen dengan $95 \%$ dari $24 \mathrm{~cm}$. Seringkali juga ukuran sepatu dinyatakan dengan 240/95, yang menggambarkan panjang kakinya $240 \mathrm{~mm}$ dan lebarnya $95 \mathrm{~mm}$ (Goonetilleke, 2012). Prinsip mondopoint juga memperhitungkan lebar kaki, sehingga sangatlah memungkinkan sistem ini lebih pas/fit daripada kebanyakan sistem lainnya (shoesizes.co, 2018). Pada penelitian ini kesesuaian ukuukuran standar dan dibandingkan dengan ukuran standar.

\section{ANALISIS DAN INTERPRETASI DATA}

\section{Data Antropometri}

Hasil penelitian ini diperoleh dari 31 wanita pekerja, yang bersedia menjadi partisipan dengan nomor sepatu 35,539,0 (Survey SPG produk kosmetik, 2018). Nomor sepatu ran sepatu yang digunakan partisipan, dikonversi ke dalam yang disebutkan oleh partisipan adalah ukuran Eropa, yang digunakannya setiap membeli sepatu. Hasil pengukuran antropometri kaki para partisipan, disajikan pada Tabel 1.

Rerata foot length hasil pengukuran partisipan dengan nomor sepatu 35,5 adalah 21,4 cm (214 mm). Bila mengacu pada sistem mondopoint (berdasarkan International Shoe Size Convertion Chart) maka dimensi panjang kaki untuk nomor 35,5 adalah $228 \mathrm{~mm}$, demikian pula nomor sepatu lainnya. Berdasarkan hasil pengukuran tersebut, terdapat perbedaan yang signifikan $(\mathrm{p}<0,05)$ antara foot length partisipan hasil pengukuran dengan ukuran berdasarkan sistem mondopoint atau Eropa (Tabel 2).

Terdapat kecenderungan ukuran foot length partisipan lebih kecil dari ukuran berdasarkan sistem mondopoint/Eropa (Gambar 3a). Maka, ukuran sepatu partisipan tidak sesuai dengan ukuran sepatu berdasarkan mondopoint/Eropa.

Hanya saja, jika panjang kaki partisipan dibandingkan dengan ukuran berdasarkan sistem mondopoint yang lebih
( 0,05) (Tabel 2). Hal ini mengindikasikan, secara umum sistem penomoran yang dilakukan oleh industri sepatu di Indonesia harus menurunkan 1 - 2 nomor dari penomoran standar tersebut (Gambar 2b dan Gambar 3c). Secara deskriptif juga dapat dilihat kesesuaiannya, karena bila diturunkan sampai 3 (Gambar 3d) nomor maka ukuran panjang hasil pengukuran lebih mendekati ke ukuran sistem mondopoint $(\mathrm{p}=0,562)$.

Panjang kaki partisipan pada nomor sepatu 37, hampir sama dengan ukuran sepatu nomor 35 pada sistem mondopoint. Berdasarkan hasil kajian data, ditemukan bahwa nomor sepatu yang dipasarkan di Indonesia hampir tidak mengikuti sistem penomoran internasional seperti yang tertera pada Tabel 2 .

Kondisi sistem penomoran seperti ini, membentuk perilaku konsumen yang tidak memiliki keyakinan dengan nomor sepatunya dan menyebabkan konsumen membutuhkan waktu yang lama saat membeli sepatu. Kondisi yang sama terjadi, bila akan membeli sepatu dengan merek lainnya. Perkembangan industri niaga yang memanfaatkan media internet dapat memudahkan konsumen dalam berbelanja, tetapi kondisi ini dapat berdampak pada potensi 
Tabel 1. Rata-rata Dimensi Antropometri Kaki untuk Shoe Last (cm)

\begin{tabular}{ccccccc}
\hline No Sepatu & Ball girth & Waist & Instep & Heel & Ankle & Foot length \\
\hline 35,5 & 18,8 & 19,8 & 20,3 & 27,7 & 18,5 & 21,4 \\
\hline 36 & 19,4 & 19,8 & 21,2 & 27,4 & 22,4 & 21,9 \\
\hline 37 & 19,4 & 21,2 & 21,8 & 28,6 & 20,5 & 22,5 \\
\hline 37,5 & 20,4 & 20,6 & 21,7 & 28,2 & 23,4 & 23,0 \\
\hline 38 & 20,4 & 21,5 & 22,0 & 29,2 & 21,4 & 23,4 \\
\hline 38,5 & 22,1 & 21,7 & 22,4 & 26,3 & 19,2 & 24,1 \\
\hline 39 & 21,0 & 22,1 & 22,9 & 28,2 & 27,6 & 24,3 \\
\hline
\end{tabular}

Tabel 2. Perbandingan Panjang Kaki Partisipan dengan Ukuran Sistem Mondopoint

\begin{tabular}{cccc}
\hline No Sepatu foot length pengukuran & $\begin{array}{c}\text { Mondopoint } \\
(\mathbf{c m})\end{array}$ & $\begin{array}{c}\text { Eropa } \\
(\mathbf{m m})\end{array}$ \\
\hline 35 & - & 22,8 & 228 \\
\hline 35,5 & 21,4 & 23,1 & 231 \\
\hline 36 & 21,9 & 23,5 & 235 \\
\hline 37 & 22,5 & 23,8 & 238 \\
\hline 37,5 & 23,0 & 24,1 & 241 \\
\hline 38 & 23,4 & 24,5 & 245 \\
\hline 38,5 & 24,1 & 24,8 & 248 \\
\hline 39 & 24,3 & 25,1 & 251 \\
\hline
\end{tabular}

Keterangan: Dimensi Mondopoint dan Eropa berdasarkan International Shoe Size Convertion Chart

kegagalan yang cukup besar pada saat konsumen membeli sepatu secara online.

\section{Perancangan Master Shoe Last}

Dimensi yang diperlukan dalam merancang master shoe last, adalah ukuran keliling ball (ball girth) dan panjang kaki (foot length). Korelasi kedua dimensi tersebut, dijadikan ukuran yang seharusnya digunakan sebagai acuan pada proses pembuatan master shoe last. Besar nilai perbandingan/rasio pada Tabel 3, menunjukkan ketidakselarasan antara peningkatan foot length dengan ball girth (Gambar 4) dan antara nomor sepatu dan rasio ball girth dengan foot length (Gambar 5). Pada Gambar tersebut, dapat dilihat nilai korelasi antara kedua dimensi tersebut tidak linier $(r=0,242)$.

Rasio ini merupakan faktor penting dalam pembuatan dan penomoran shoe last, dengan kata lain perlu mempertimbangkan pembuatan shoe last untuk kaki kurus (slim foot), kaki normal dan kaki lebar (barefoot). Oleh karena itu, pada proses pembuatan shoe last tidak dapat dilakukan tahap pembuatan grading nomor secara masinal. Perlu diupayakan untuk selalu memperhatikan ball girth pada di setiap nomor, sehingga ada kesesuaian dengan kondisi bentuk kaki.

Sistem penomoran terhadap ball girth, telah dikembangkan dan diterapkan dengan membedakan ukuran sepatu berdasarkan lebar kaki dengan notasi B (kurus), C (standard/ medium), D - E (lebar) dan EE - EEE atau 2E - 3E (ekstra lebar). Gambar ukuran lebar sepatu wanita, yang mengacu pada ball girth dapat dilihat pada Gambar 6. Notasi tersebut untuk menentukan ukuran lebar sepatu wanita, sedangkan ukuran lebar sepatu pria adalah D (kurus), E (standard/ medium), EE atau 2E (lebar), 3E (ekstra lebar) dan 4E (ekstra - ekstra lebar).

Penomoran lebar sepatu, yang mengacu pada ball girth belum diterapkan dalam sistem penomoran sepatu di Indonesia. Rasio ball girth dan foot length wanita Jepang, lebih besar daripada wanita Perancis (Baba, 1975). Hasil pengukuran menunjukkan, bahwa rasio ball girth dan foot length wanita Indonesia berbeda dengan wanita Jepang (Gambar 7). Rasio ball girth dan foot length wanita Indonesia, lebih kecil daripada wanita Jepang. Hal ini mengindikasikan, bahwa perlu dilakukan penomoran lebar sepatu melalui penyesuaian terhadap anatomi kaki wanita Indonesia.

\section{Penentuan Ukuran untuk Pembuatan Master Shoe Last}

Pada hasil observasi ditemukan bahwa pembuatan shoe last oleh para pengrajin di sentra IKM alas kaki, memakai pendekatan/cara yang berbeda. Umumnya, pengrajin mulai dengan menetapkan jenis sol yang akan digunakan. Selanjutnya, pembuat shoe last mengikutinya. Pada metoda ini penomoran ditentukan oleh produsen sol, tetapi ternyata ada pula pengrajin yang mengingingkan penomoran ditentukan oleh pembuat shoe last. Pada umumnya, para pengrajin memercayakan penomoran pada pembuat shoe 


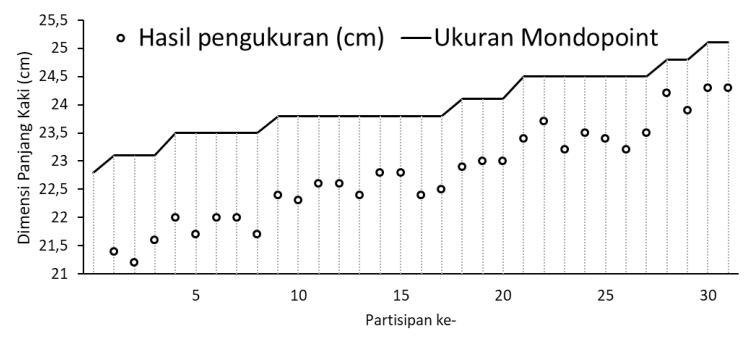

(a)

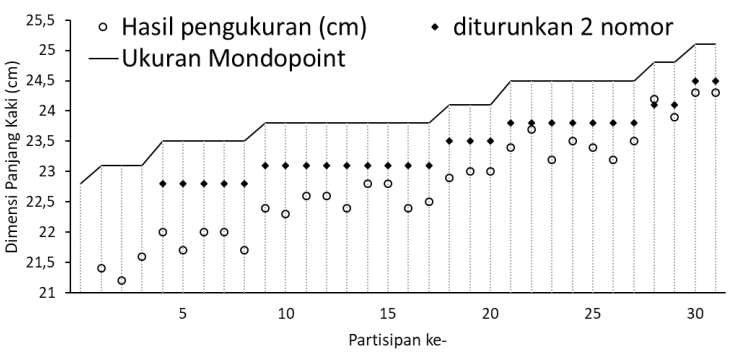

(c)

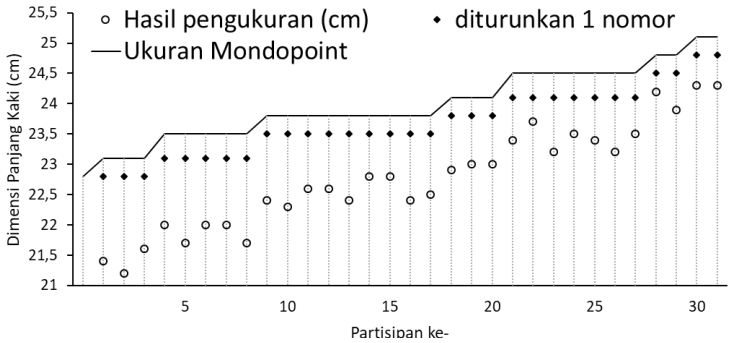

(b)

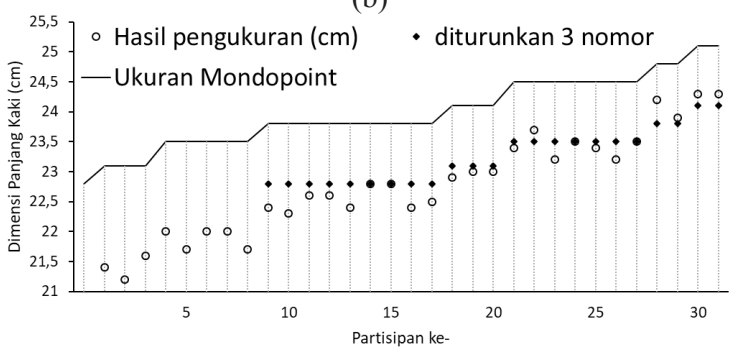

(d)

Gambar 3. Posisi hasil pengukuran terhadap ukuran mondopoint

Tabel 3. Table korelasi Panjang dan Keliling Ball Kaki untuk Shoe Last (cm)

\begin{tabular}{rccc}
\hline No Sepatu & ball girth & Foot length & Rasio \\
\hline 35,5 & 18,8 & 21,4 & 0,88 \\
\hline 36 & 19,4 & 21,9 & 0,89 \\
\hline 37 & 19,4 & 22,5 & 0,86 \\
\hline 37,5 & 20,4 & 23,0 & 0,89 \\
\hline 38 & 20,4 & 23,4 & 0,87 \\
\hline 38,5 & 22,1 & 24,1 & 0,92 \\
\hline 39 & 21,0 & 24,3 & 0,86
\end{tabular}

last tanpa perlu melakukan verifikasi (Sunarya, 2018). Hal ini menunjukkan, bahwa terdapat kontribusi proses pembuatan shoe last terhadap ketidakseragaman sistem penomoran sepatu di Indonesia.

Beberapa produsen sepatu, hanya menyediakan sepatu dengan nomor bulat sehingga pengguna sepatu yang bernomor setengah lebih banyak tidak terakomodir. Hal ini menyebabkan konsumen harus memilih sepatu dengan nomor yang lebih besar dari ukuran kakinya, yang berdampak pada ketidaknyamanan. Keengganan produsen sepatu menyediakan shoe last bernomor setengah, karena terjadi peningkatan biaya pembuatan shoe last.

Data antropometri yang dapat digunakan untuk pembuatan master shoe last adalah panjang kaki/ foot length, ball girth, keliling instep dan keliling heel (Tabel 2). Proses perancangan dan pembuatan master shoe last, dimulai dari proses analisis dimensi foot length dan ball girth. Sedangkan dimensi keliling heel dan keliling instep, harus digunakan untuk validasi ukuran jika shoe last telah selesai dibuat.

Ukuran sepatu yang paling dominan menurut hasil survey adalah nomor 37 (29\%) dan nomor 38 atau 22,6\% (Gam- bar 8). Walaupun jumlah partisipan pada penelitian ini belum dapat mewakili populasi wanita bekerja, metoda ini dapat digunakan untuk menentukan jumlah ukuran shoe last yang harus disediakan. Jumlah shoe last yang harus dimiliki produsen sepatu merupakan investasi yang cukup besar, sehingga metoda sensus dapat digunakan untuk menentukan proporsi persediaan shoe last. Seperti yang telah dilakukan pada penelitian ini, maka teknik sensus dilakukan dengan pengukuran antropometri kaki konsumen secara langsung.

\section{Konsekuensi Proses dan Sistem Penomoran Shoe Last Saat Ini}

Adanya fenomena ketidakseragaman ukuran dan bentuk pada shoe last yang digunakan oleh industri alas kaki, maka perlu dilakukan upaya untuk merancang master shoe last yang datanya mengunakan data antropometri sebagai acuan. Master shoe last tersebut, harus dirancang sesuai dengan data antropometri kaki hasil survey.

Berdasarkan hasil pengukuran (Tabel 1), maka outline bentuk kaki ditunjukkan pada Gambar 9a yang berbentuk garis pada gambar shoe last. Pada kasus ini, digunakan shoe last untuk sepatu berhak tinggi (high heel). Berdasarkan outline tersebut, dapat dilihat bahwa kedudukan arch 


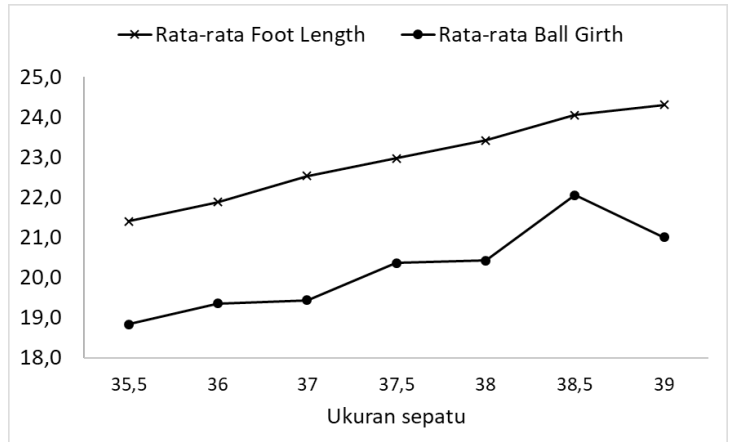

Gambar 4. Rata-rata ball girth dan foot length
- Rasio Ball Girth - Foot Length --.--.-- Linear (Rasio Ball Girth - Foot Length)

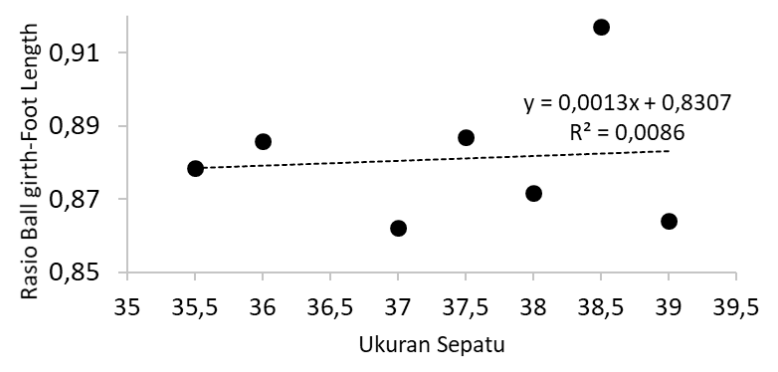

Gambar 5. Peningkatan Nomor Sepatu dan Rasio ball girth foot length

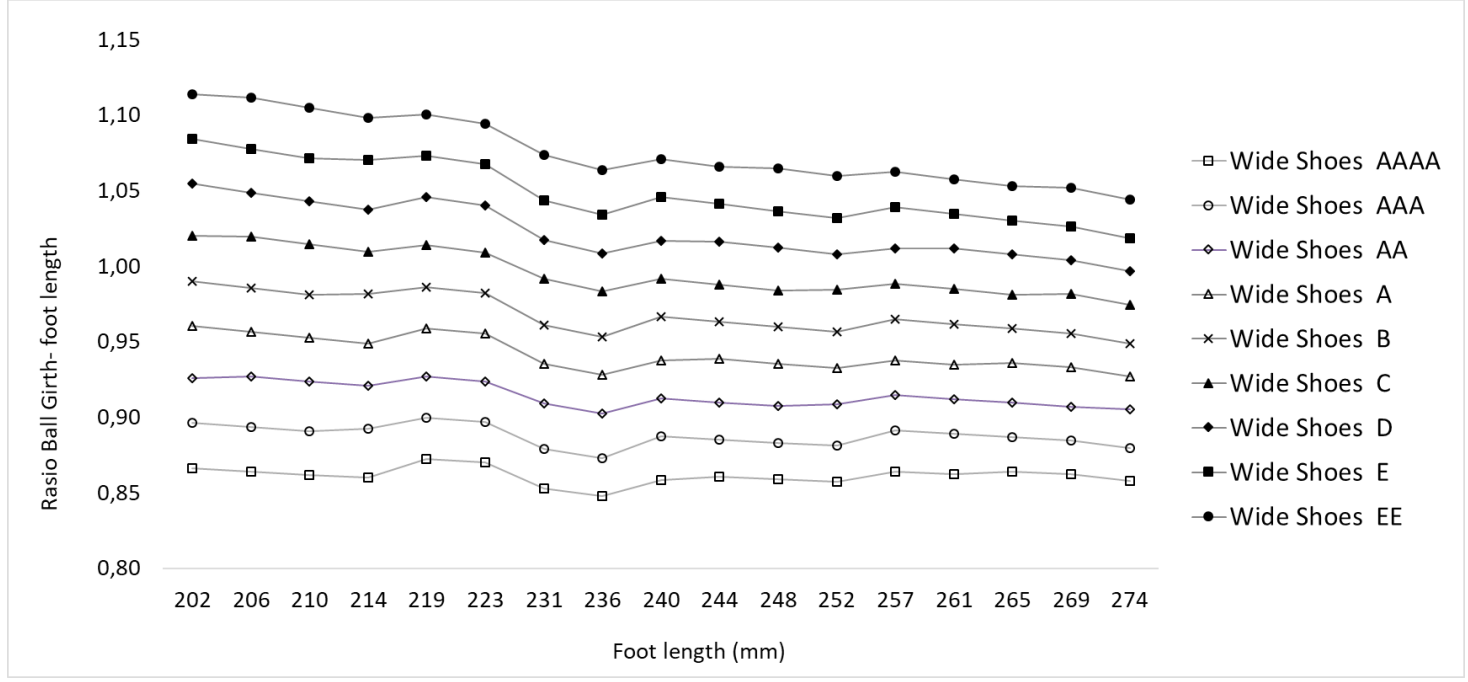

Gambar 6. Ukuran Lebar Sepatu Wanita berdasarkan mondopoint system

kaki pada sepatu yang memiliki ketinggian hak tertentu ditemukan beberapa ketidaktepatan bentuk. Oleh karena itu, perlu dilakukan perbaikan atau penyesuaian pada bagian tersebut sehingga sesuai dengan karakter kaki dan data antropometri yang sudah diperoleh (Gambar 9b).

Pada umumnya, penyesuaian bisa dilakukan pada bagian sebagai berikut.

1. Area punggung kaki (instep): karena adanya perubahan bentuk kaki saat menjejak/menginjak pada posisi menggunakan sepatu dengan tinggi hak berbeda.

2. Lengkungan kaki (arch) pada bagian plantar: karena terdapat bentuk arch yang berbeda-beda dan dapat berubah tergantung ketinggian hak.

3. Bagian atas dari tumit (Gambar 9b): karena pada bagian ini dapat memengaruhi kesesuaian "pencekaraman" dinding back counter sepatu pada tumit kaki sehingga sepatu tidak mudah terlepas ketika digunakan saat berjalan.

\section{Identifikasi Kekritisan Bentuk Shoe Last}

Kesalahan shoe last bukan hanya berdampak pada kenyamanan, tetapi juga pada bentuk sepatu yang dihasilkan. Bentuk sepatu merupakan aspek visual yang penting dalam produk fesyen, khususnya yang berkaitan dengan unsur komposisi seperti keselarasan, proporsi dan image produk (citra visual). Jenis kesalahan pembentukan master shoe last, pada umumnya terdiri atas:

Bentuk toe box atau bagian depan sepatu, sebagai bagian yang sering berkaitan dengan bentuk dasar jenis sepatu atau jenis sandal. Sesuai dengan bentuk kaki saat menggunakan sandal, maka kontur penampang shoe last menyerupai posisi normal dari jari-jari kaki yang agak cenderung melebar (Gambar 10b). Tuntutan tampilan elegan ditunjukkan dengan ujung sepatu yang runcing, sehingga kontur toe box sepatu dibuat runcing (Gambar 10a).

Bentuk toe box, terutama pada shoe last untuk high heel harus dilandasi prinsip biomekanika saat memakai high heel menunjukkan bahwa posisi kaki memengaruhi bentuk sepatu yang akan dibuat. Hal ini berdampak pada bentuk atau visual high heel pada saat sebelum, saat, maupun setelah digunakan. Gambar 11a menunjukkan shoe last yang tidak proporsional dengan posisi toe-box shoe last, karena lebih tinggi $2 \mathrm{~cm}$. Bentuk toe-box shoe last untuk sepatu ber-hak, jika dibuat secara proposional ditunjukkan pada Gambar 11b. 


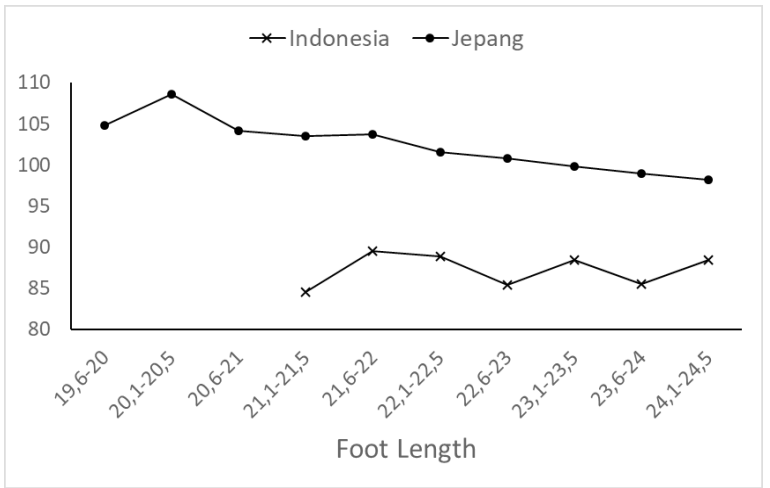

Gambar 7. Rasio ball girth dan foot length wanita Indonesia dan Jepang

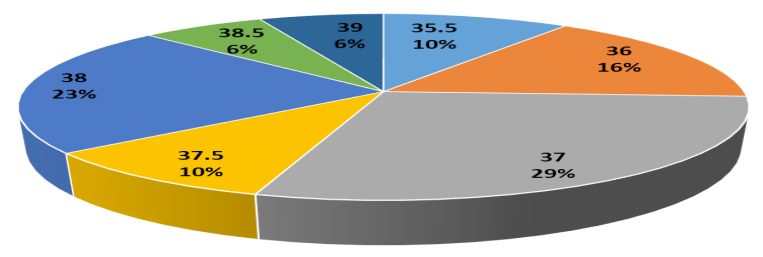

Gambar 8. Persentase ukuran sepatu wanita

Bentuk back counter atau tumit master shoe last untuk sepatu jenis pump, menentukan kemampuan sepatu untuk mencengkeram tumit agar sepatu melekat erat pada tumit kaki tanpa mengurangi kenyamanan. Gambar 11 menunjukkan bentuk back counter master shoe last, yang salah dengan outline kaki pada saat menggunakan sepatu. Bentuk back counter yang tidak sesuai, bisa mengubah konstruksi sepatu dan posisi kaki saat memaki sepatu. Bentuk dan ukuran back counter master shoe last harusnya dibuat lebih ramping dibandingkan dengan pergelangan kaki, agar sepatu dapat mencengkeram pergelangan kaki dengan baik pada saat dikenakan.

\section{Rancangan Master Shoe Last berdasarkan Karakter-} sistik Antropometri Kaki Wanita Indonesia

Berdasarkan hasil observasi dan survey terhadap dimensi antropometri kaki wanita, maka perlunya dilakukan perancangan ulang shoe last yang akan dibuat sebagai shoe last master. Pada penelitian ini, sudah dirancang master shoe last untuk high heel untuk nomor 37 dan 37,5 dengan spesifikasi sebagai berikut:

- $\quad$ Panjang kaki : 22,6 cm

- Keliling ball : 19,7 cm

- Keliling waist : 21,0 cm

- Keliling instep : $21,8 \mathrm{~cm}$

- Keliling heel : $28,5 \mathrm{~cm}$

- Lebar tumit : $5,4 \mathrm{~cm}$

- Lebar tumit atas : $2,9 \mathrm{~cm}$

Mengacu pada dimensi antropomteri dan karakter kaki wanita Indonesia saat menggunakan high heel, maka desain master shoe last untuk high heel bagi wanita Indone-

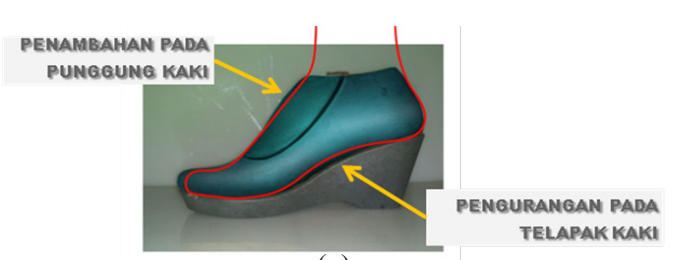

(a)

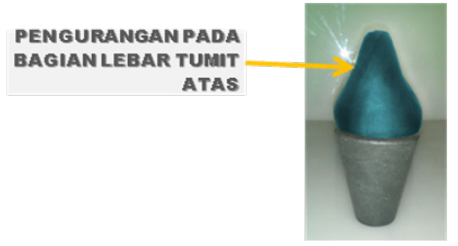

(b)

Gambar 9. Outline dan penyesuaian bentuk kaki berdasarkan data antropometri kaki

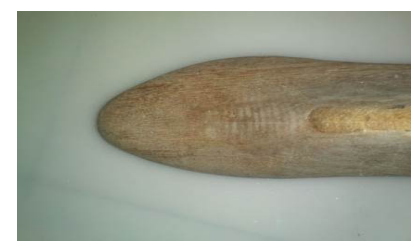

a. shoe last sepatu

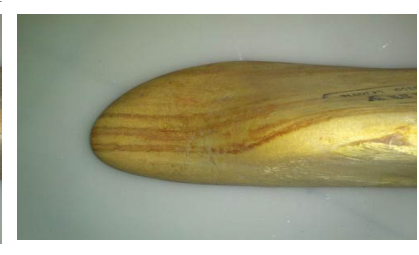

b. Shoe last sandal
Gambar 10. Perbedaan bentuk toe box shoe last (Sumber: Dok. Pribadi) sia dapat dilihat pada Gambar 12.

\section{Rancangan Master shoe last berdasarkan karaktersistik antropometri kaki wanita Indonesia}

Berdasarkan hasil observasi dan survey terhadap dimensi antropometri kaki wanita, maka dilakukan perancangan ulang shoe last yang akan dibuat sebagai shoe last master. Pada penelitian ini akan dirancang master shoe last untuk high heel dengan nomor 37 dan 37,5 dengan spesifikasi:

$\begin{array}{lll}\text { - } & \text { Panjang kaki } & : 22,6 \\ \text { - } & \text { Kel. Ball } & : 19,7 \mathrm{~cm} \\ \text { - } & \text { Kel Waist } & : 21,0 \mathrm{~cm} \\ \text { - } & \text { Kel. Instep } & : 21,8 \mathrm{~cm} \\ \text { - } & \text { Kel. heel } & : 28,5 \mathrm{~cm} \\ \text { - } & \text { Lebar tumit } & : 5,4 \mathrm{~cm} \\ \text { - } & \text { Lebar tumit atas } & : 2,9 \mathrm{~cm}\end{array}$

Contoh master shoe last hasil verifikasi bentuk dan ukuran yang merujuk pada data anthropometri kaki pekerja wanita Indonesia dapat dilihat pada Gambar 12.

\section{SIMPULAN}

Faktor ketidaknyamanan sepatu yang di produksi oleh IKM di Indonesia, umumnya dipengaruhi desain master shoe last yang salah. Kesalahan tersebut, dimulai dari sistem penomoran yang tidak sesuai dengan acuan sistem pengukuran manapun bahkan bentuk yang tidak mengikuti karakteristik bentuk kaki orang Indonesia. Pada penelitian ini ditemukan hasil, bahwa ukuran yang diterapkan pada shoe last tidak sesuai dengan ukuran pada sistem penomoran mondopoint dan Eropa. Selain itu master shoe last 


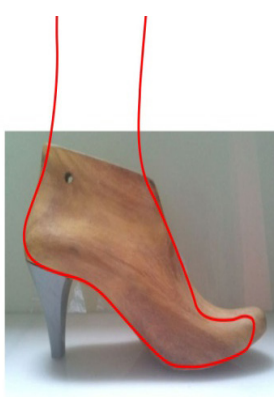

(a)

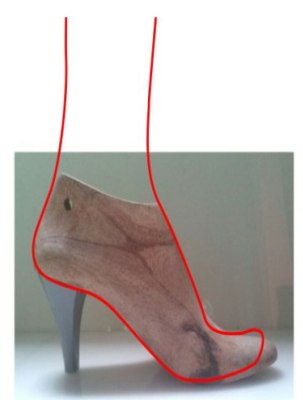

(b)
Gambar 11. Outline Posisi toe-box pada master shoe last untuk High Heel (Sumber: Dok. Pribadi)
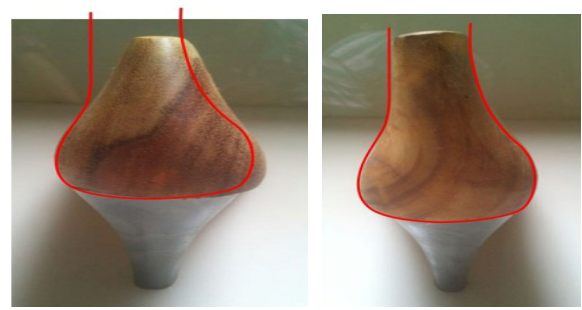

Gambar 11. Outline back counter master shoe last (Sumber: Dok. Pribadi)

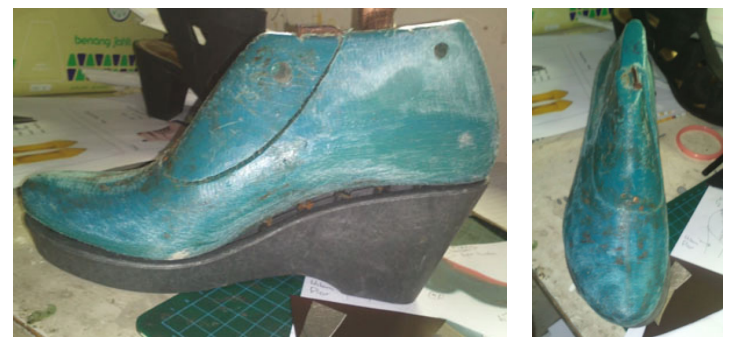

Gambar 12. Contoh Prototype master shoe last hasil verifikasi/ penyempurnaan bentuk (Sumber: Dok. Pribadi)

yang dirancang belum memperhatikan ball girth menyebabkan konsumen harus menaikkan nomor sepatu untuk meningkatkan kenyamanan pada titik metatarsal.

Proses pembentukan master shoe last oleh pengrajin, juga kurang memerhatikan perubahan bentuk kaki sesuai dengan kebutuhan alas kaki (sepatu atau master shoe last sandal) dan postur akibat menggunakan sepatu ber-hak. Bentuk juga tidak mendukung untuk membentuk sepatu yang mampu mencengkeram tumit dengan baik.

Prototipe master shoe last, diharapkan dapat digunakan sebagai dasar dalam penetapan ukuran dan bentuk sepatu high heel. Rancangan master shoe last harus mengacu pada antropometri dan karakteristik kaki wanita Indonesia pada saat memakai high heel, agar sepatu yang dihasilkan selalu dapat memberikan kenyamanan pada saat digunakan.

\section{DAFTAR RUJUKAN}

Azhari, M. A., Wahyuning, C. S., \& Irianti, L. (2015). Rancangan Produk Sepatu Olahraga. Reka Integra No.04, Vol.03, 241-252.
Baba, K. (1975). Foot Measurement for Shoe Construction with reerence to the Relationship Between Foot Length, Foot Breadth, and Balll Girth. Journal Human Ergology, Vol. 3, 149-156.

Barnish, M. S., \& Barnish, J. (2016). High-heeled Shoes And Musculoskeletal Injuries: A Narrative Systematic Review. BMJ Open, 6, e010053.

Finding the right shoe size with Sioux. (2018, July 29). Retrieved from Sioux: https://www.sioux.de/en/shoe-knowhow/shoe-size-and-fit/shoe-size-conversion/

Gerdes, A. (2013). AG Leathers. Retrieved from http:// www.agleathers.com/:http:// www.agleathers.com/product/free-e-book-shoes-dont-fit/

Goonetilleke, R. S. (2012). The Science of Footwear. CRC Press.

Lee, S. (2011). Combined Effects of High-heeled Shoes and Load Carrriage on Gait and Posture in Young Healthy Women. Ottawa: School of Human kinetics Faculty of Health Sciences University of Ottawa.

Lin, L.-Y., \& Chen, C.-H. (2015). Innovation and Ergonomics Consideration for Female Footwaear Design. Procedia Manufacturing 3, 5867-5873.

Mardani, R. (2014). Analisis Kesesuaian Antropometri Kaki Orang Indonesia dengan Ukuran Sepatu British, Amerika, dan Eropa. Yogyakarta: Universitas Gajah Mada.

Pivecka, J. (1994). Practical Handbook on Shoe Production. Eschborn: Protrade: Footwear and Leathergoods Division.

Shoesizes.co. (2018, July 30). Retrieved from The Official International Shoe size Conversion Chart: http://www. shoesizes.co/

Sulistyadi, K., \& Susanti, S. L. (2003). In Perancangan Sistem Kerja dan Ergonomi. Jakarta: Departemen Pendidikan Nasional Direktorat Jenderal Pendidikan Tinggi Jurusan Teknik Industri Fakultas Teknik Universitas Sahid.

Sunarya, D. (2018, February 12). Cara pembuatan shoe last sepatu. (M. A. Waskito, Interviewer)

Waskito, M. A., \& Wahyuning, C. S. (2013). Perancangan Master She Last Seagai Usaha Meningkatkan Kualitas Ergonomi Poduk Sepatu Wanita yang Dikembangkan Melallui Metoda Quality Function Deployment. Bandung: LPPM - Itenas.

Younus, D. M., Ali, D., Memon, D. A., Ismail, D., \& Qazi, D. (2014). High Heel Shoes; Outcome of Wearing in Young Generation:A Cross Sectional Study. The Professional Medical Journal, 7. 